\title{
Gonadotropin and Testosterone hormone's serum levels and partial deletions in the AZFc region in Iranian oligozoospermia infertile males
}

\author{
Nasser Salsabili ${ }^{*}$, Reza Mirfakhraei ${ }^{2}$, Maryam Montazeri $^{3}$, Mitra Ataei $^{2}$, Paricheher Yaghmaei $^{2}$, \\ Gholamreza Pourmand ${ }^{4}$ \\ ${ }^{1}$ IVF Department of Mirza Kouchak Khan Hospital, Rehabilitation Faculty, Tehran University of Medical Sciences, Tehran, Iran; \\ *Corresponding Author: dr.salsabili56@yahoo.com \\ ${ }^{2}$ Department of Biology, Islamic Azad University (IAU), Science and Research Branch, Tehran, Iran; \\ ${ }^{3}$ Department of Medical Genetic, National Institute of Genetic Engineering and Biotechnology, Tehran, Iran; \\ ${ }^{4}$ Urology Research Center, Sina Hospital, Tehran University of Medical Sciences, Tehran, Iran.
}

Received June 12 $2^{\text {th }}$ 2011; revised July 26 $6^{\text {th }}, 2011$; accepted August $10^{\text {th }}, 2011$.

\begin{abstract}
To investigate the relation of luteinizing hormone (LH), follicle-stimulating hormone (FSH) and Testosterone serum levels with partial deletions in the AZFC region in Iranian oligozoospermia males. Material and methods: thirty infertile oligozoospermia and 52 Iranian fertile men included. The hormonal assays were measured by the Radioimmunoassay (RIA). Multiplex polymerase chain reaction (M-PCR) using eight sequence-tagged site (STS) markers were measured on the Yq11 chromosome. Results: The mean of FSH and LH levels in all oligozoospermia males were higher than fertile men $(p<$ 0.001 ) and testosterone was lower significantly $(p<0.001)$. Five patients showed partial deletions in AZFc region (four had gr/gr and one had b2/b3 deletions). Six fertile men showed partial deletions (five gr/gr and one b2/b3) with higher level of FSH, LH in their group $(p<0.05)$. Conclusion: According to high incidence of partial deletions in the AZFc region among Iranian oligozoospermia males, hormonal assay and molecular screening should be advised before considering for ART treatments.
\end{abstract}

Keywords: Oligozoospermia; Gonadotropin Hormone; AZFc Partial Deletion

\section{INTRODUCTION}

Male fertility is the end results of numerous and varied processes which all must act in perfect concert to allow the deposition of healthy sperm in to the female reproductive tract. If any of these co-dependent steps is faulty, infertility may result.

At least $30 \%-50 \%$ of couples with primary infertility will have a male related problem as the sole or partial reason for their infertility. Germ cell development is dependent on the balanced endocrine interplay of the hypothalamus, the failure of pituitary to secret FSH and LH will result in disruption of testicular function leading to infertility [1-3]. In addition, Yq, long arm of Y chromosome, contains at least one gene that is responsible for spermatogenesis [4]. Several genes are located in the azoospermia factor region (AZF) on four major intervals defined as AZFa, AZFb, AZFc and AZFd [5-8]. Partial deletions of the AZFc region are reported as a significant risk factor for oligozoospermia. AZFc, the most frequently known genetic causes of impaired spermatogenesis, is mapped between deletion intervals $6 \mathrm{C}$ and $6 \mathrm{E}$ on $\mathrm{Y}$ chromosome.

Deletion in this region is found in $2 \%-10 \%$ of azoospermic or severely oligozoospermic men $[5,8]$. The AZFc region removes $3.5 \mathrm{Mb}$ and contains seven gene families which have an important role in spermatogenesis [9]. The existence of the three subdeletions; namely gr/gr, b1/b3 and b2/b3 have been confirmed by using the new molecular markers [10].

The AZFc region is occupied halfly by the gr/gr type, which spans $1.6 \mathrm{Mb}$; it is thought to be a risk factor for spermatogenic failure [11]. It is found that the direct homologous recombination causes this kind of the subdeletion which also accounts for another type, b1/b3 deletion $(1.6 \mathrm{Mb})$ [10,11]. An inversion event is responsible for two other types which are belonging to the $2^{\text {nd }}$ class. The gr/rg inversion is followed by a b2/b3 deletion (1.8 Mb), while the b2/b3 inversion is followed by a gr/gr deletion (1.8 Mb) [12] or g1/g3 deletion (2.2 Mb) [11]. 
The aim of this study is to investigate Testosterone, FSH, LH serum levels and the prevalence of partial deletions in the AZFc region (gr/gr, b1/b2, and b2/b3) in Iranian oligozoospermia males.

\section{MATERIAL \& METHODS}

Thirty infertile oligozoospermia with at least 3 year's duration of infertility referred from Mirza Kouchek Khan hospital and Koasar fertility and impotency center. In all the oligozoospermia cases sperm concentration was $(<20 \mathrm{mil} / \mathrm{ml})$ with normal karyotypes. Female partners were examined for their fertility using hormonal evaluation for ovarian function and laparoscopy for the confirmation of tubal patency. Only those couples where the male partner was found to be oligozoospermia and the female was normal selected for the study. Fifty two normal fertile men with normal karyotypes and sperm concentration $(<20 \mathrm{million} / \mathrm{ml})$ were selected as control group. The hormonal assays were measured by the Radioimmunoassay (RIA), and for the presence of eight sequence-tagged site (STS) markers on the Yq11 chromosome, Multiplex polymerase chain reaction (M-PCR) was used. An informed written consent was obtained from all subjects for molecular screening and hormonal Assay.

\subsection{Specimen Collection}

$10 \mathrm{ml}$ of peripheral blood was collected in a sterile tube containing ethylene diamine tetra acetate (EDTA) as an anticoagulant and divided into two parts:

1) $7 \mathrm{ml}$ was centrifuged (2500 g rpm) for 5 minutes and serum was stored at $-20^{\circ} \mathrm{C}$ for hormonal assay.

2) $3 \mathrm{ml}$ was used for DNA extraction.

\subsection{Assay Hormones}

Serum levels of luteinizing hormone (LH), folliclestimulating hormone (FSH) and testosterone were collected early in the morning and evaluated at the Mirza kouch khan hospital pathology reference services.

In all subjects, serum levels of LH were measured by radioimmunoassay kit (Amersham Corp., Arlington Heights, Illinois, USA).Reference ranges were 4 to 23 $\mathrm{mIU} / \mathrm{ml}$. Similarly, serum levels of FSH were determined by radioimmunoassay kit. Reference ranges were 10 to $76 \mathrm{mIU} / \mathrm{ml}$. and for serum levels of testosterone were determined by radioimmunoassay kit (Amersham Corp., Arlington Heights, Illinois, USA) with reference ranges were 0.2 to $11 \mathrm{ng} / \mathrm{ml}$.

\subsection{Molecular Screening}

Genomic DNA was extracted from peripheral blood using Tadbir Azma DNA extraction kit (Tadbir Azma, Tehran, Iran). First of all, we investigated classical AZF microdeletions; consequently, the polymerase chain reaction was used to detect 8 different sequence tag sites (STS) corresponding to different AZF loci according to the European Academy of Andrology (EAA), the European Molecular Genetics Quality Network (EMQN) (13). These included sY84 and sY86 (AZFa); sY127and sY134 (AZFb); sY254 and sY255 (AZFc); and sY145 and sY153 (AZFd). These STSs were analyzed using three different M-PCRs:

Multiplex 1: sY86, sY127, sY254, and ZFY;

Multiplex 2: sY84, sY134, sY255, and SRY;

Multiplex 3: sY145, SY154, and SRY.

Two primers (ZFY, SRY) were used as internal controls for M-PCR. Primers sequences with additional details are provided in a previous study [14]. The reaction was comprised of 50 - 100 ng of genomic DNA in 25 ul PCR reactions, $10 \mathrm{mM}$ Tris $\mathrm{HCl}$ (pH 8.3), $50 \mathrm{mM} \mathrm{KCl}$, $1.5 \mathrm{mM} \mathrm{MgCl}_{2}$, 2 mmol dNTPs, 10 pmol of each primers and 1unit of Taq DNA polymerase. Initial denaturetion step at $94^{\circ} \mathrm{C}$ for $5 \mathrm{~min}$, followed by 28 cycles of $94^{\circ} \mathrm{C}$ for $30 \mathrm{sec}, 56^{\circ} \mathrm{C}$ for $30 \mathrm{sec}$ and $72^{\circ} \mathrm{C}$ for $45 \mathrm{sec}$ ending with a final extension for $5 \mathrm{~min}$ at $72^{\circ} \mathrm{C}$.

The PCR products were separated on $2 \%$ agarose gels stained with ethidium bromide, or $10 \%$ acrylamide gel prepared in 0.5X TBE. In all reactions, DNA from a normal woman and a normal man were included as controls.

The samples without classical AZF deletions were investigated in order to find gr/gr, b1/b2, and b2/b3 polymorphisms. The presence or absence of these subdeletions was analyzed using M-PCR. Two STS markers were detected for the study and were tested in one M-PCR: SRY, SY1191, and SY1291.The sequence of the primers is shown in Table 1. Reaction condition and PCR program was similar to the program used for detection of classical AZF. The PCR products were separated on 2\% agarose gel. The absence of amplification of sY1291 represented a gr/gr deletion and the absence of sY1191 product showed b2/b3 deletion. Deletion of the two markers was defined as b1/b3 deletion.

\subsection{Statistical Analysis}

Independent Student's t-Test was used to compare the numerical values of blood plasma hormonal assay in both groups. All procedures were carried out using SPSS for Windows V11.5. The type 1 error was set at 0.05 for testing the hypothesis.

\section{RESULTS}

The FSH and LH levels in oligozoospermic group 
men were significantly increased ( $p<0.001)$. The mean value of testosterone levels significantly decreased in oligozoospermic men in compare with fertile men $(p<$ 0.001) (Table 2).

Totally, only 1 out of 30 oligozoospermic men (3.3\%) with spermatogenesis impairment was found to have classical AZFb deletion. The gr/gr, b2/b3 and b1/b3 subdeletions in all subjects were determined using M-PCR.

After having eliminated 1 classical AZFb deletions from 30 oligozoospermic men, subdeletions in the AZFC region; was found in 4cases (13.8\%) gr/gr subdeletions, $1(3.4 \%)$ b2/b3 subdeletions and $0(0 \%)$ b1/b3 subdeletions.

In contrast, screening of 52 control fertile men revealed 5(9.6\%) gr/gr subdeletions, $1(1.9 \%)$ b2/b3 subdeletions and $0(0 \%) \mathrm{b} 1 / \mathrm{b} 3$ subdeletions. There was no significant difference in the frequency of the gr/gr and b1/b3 subdeletions between the patients and controls ( $p>$ 0.05).

The mean value for FSH, $\mathrm{LH}$ and testosterone concentration in normal fertile men was $7.48 \mathrm{mIU} / \mathrm{ml}, 6.73$ $\mathrm{mIU} / \mathrm{ml}$ and $3.93 \mathrm{ng} / \mathrm{ml}$ respectively (Table 2). In 4 oligozoospermia infertile men with gr/gr subdeletion; FSH, LH was higher and clearly subnormal testosterone is shown (Table 3).

\section{DISCUSSION}

Hormonal assay of the FSH, LH and testosterone is useful in the management of the male infertility, and for initiation of spermatogenesis and maturation of spermatozoa $[3,15]$. In the oligozoospermic men higher concentration of FSH is considered to be a reliable indicator of germinal epithelial damage or primary testicular failure $[7,8]$. Moreover, different studies have reported that serum FSH and LH were significantly above the mean value in infertile oligozoospermic men with Y-chromosome microdeletion $[6,16]$.

In the present study, the same results were obtained and FSH, LH in oligozoospermia patients were signifycantly higher than fertile group and testosterone values was lower $(p<0.001)$, this indicates primary testicular failure in our oligozoospermia men. Five oligozoospermia patients showed partial deletions in AZFc region (4 had gr/gr and one had b2/b3 deletions).

Combination of gr/gr subdeletion and sub normal testosterone serum level was not explained by any other investigators $[17,20]$. In opposite of some previous studies $[17,18,20]$, these values were significantly different in infertile oligozoospermia males with AZFc subdeletions. Different results obtained from the present study

Table 1. STS markers and primer sequences used for screening gr/gr, b1/b2, and b2/b3 polymorphisms.

\begin{tabular}{cccc}
\hline STS & AZF & Production Size(bp) & sequence \\
\hline \multirow{2}{*}{ sY1191 } & AZFc & 385 & 5'-CCAGACGTTCTACCCTTTCG-3 \\
& & & 5'-GAGCCGAGATCCAGTTACCA-3' \\
\multirow{2}{*}{ sY1291 } & AZFc & 527 & 5'-TAAAAGGCAGAACTGCCAGG-3' \\
& & 5'-GGGAGAAAAGTTCTGCAACG-3' \\
\hline
\end{tabular}

Table 2. Serum FSH, LH and testosterone levels in fertile and oligozoosperic men.

\begin{tabular}{ccccc}
\hline \multirow{2}{*}{ Group } & \multirow{2}{*}{ No. subjects } & \multicolumn{2}{c}{ Hormonal levels mean(SD) } \\
\cline { 3 - 5 } & 52 & $\begin{array}{c}7.48 \pm 4.21 \\
\text { Range }(2.50-18)\end{array}$ & $\begin{array}{c}6.73 \pm 3.73 \\
\text { Range }(2.10-18.30)\end{array}$ & $\begin{array}{c}\text { Range }(2.20-8.25) \\
\text { Fertile men }\end{array}$ \\
$\begin{array}{c}\text { Infertile men } \\
\text { (Oligozoospermia) }\end{array}$ & 30 & $\begin{array}{c}20.28 \pm 11.59^{*} \\
\text { Range }(4.50-40)\end{array}$ & $\begin{array}{c}14.67 \pm 7.29^{*} \\
\text { Range }(3.80-35)\end{array}$ & $\begin{array}{c}3.11 \pm 1.67 * \\
\text { Range }(0.80-8.50)\end{array}$ \\
\hline
\end{tabular}

${ }^{*} p<0.001$.

Table 3. Clinical features of 4 oligozoospermia men with gr/gr subdeletion.

\begin{tabular}{cccccc}
\hline Patient No & Sub deletion & FSH mIU/ml & LH mIU/ml & Testosterone ng/ml & Sperm count mil/ml \\
\hline 7 & gr/gr & 36 & 15 & 2.60 & $1 \times 10^{6}$ \\
8 & gr/gr & 37 & 20 & 2.60 & $1 \times 10^{6}$ \\
22 & $\mathrm{gr} / \mathrm{gr}$ & 40 & 17 & 1.50 & $5 \times 10^{6}$ \\
26 & $\mathrm{gr} / \mathrm{gr}$ & 37 & 22 & 2.50 & $3 \times 10^{6}$ \\
\hline
\end{tabular}


may be due to limitation in sampling or oligozoospermia classification.

The FSH producing by pituitary is affected by the Inhibin B feed-back control [17], which is produced by the sertoli cells. In the patients with the germinal cells function deficiency, the inhibin rate will be reduced while the FSH rate will be increased. Indeed, this is a possible interaction between the germinal and sertoli cells. The serum FSH rate is related to the epithelium function of the germinal cells [18]. Additionally, It is commonly approved that complete deletion of $\mathrm{Y}$ chromosome is a determining factor of sever spermatogenesis disorder. And the relationship between partial deletions of AZFC region and male sterility is to be discussed $[6,19]$.

Furthermore many studies have been carried out for detecting the relationship between subdeletions and sterility in recent years $[13,14,18,20]$; however the results in different populations were not identical. In the present survey no significant differences were detected for the frequencies of gr/gr and b2/b3 deletions in the studied groups $(p>0.05)$.

According to the surveys carried out on a population in East Asia the frequency of gr/gr deletion in terms of prevalence percentage were estimated respectively as $10.3 \%$ and $10.1 \%[12,21]$, that is comparable with our result. The only deletion which is created through gr/gr recombination is the significant cause of spermatogenesis failure [14].

Men with AZFc subdeletion are somatically healthy with most likely have useable sperm, stable sperm production over time and a good chance to experience biological paternity. However, their sons would also be AZFc subdeletion carrier $[14,16,19,20]$. In our study, b2/b3 frequency equated to $3.4 \%$ showing no significant difference in comparison to the frequency of these subdeletions in fertile population. In all the previous studies, no significant relationship was detected between the prevalence of this deletion and sterility which can be due to the racial differences among populations [19,21]. Furthermore the present study may be in conflict with similar studies or other surveys [14,19]. The role of b2/b3 deletions in male sterility is still unknown because of its low frequency. It seems that the role of DAZ3/4 deletion in male sterility is limited to the b2/b3 subdeletion [14,22]. Therefore; more studies should be done for detecting the role of gr/gr deletion and b2/b3 subdeletion in the context of Y haplogroups. However, there are different factors which influence the results of the studies. Observed differences in the deletions of AZFc region in various studies can be due to diverse demographic composition, differences in criteria for selection of patients, environmental impacts and also the categorization method applied for the definition of oligozoospermia due to dif- ferent classification depend on the sperm count and characteristics [22]. Vogt considered the oligozoospermic criteria less than $2 \mathrm{mil} / \mathrm{ml}$ sperm in his study [7]. In Other investigations oligozoospermic criteria was considered less than one $\mathrm{mil} / \mathrm{ml}$, which obviously can highly influence the results of the studies [23,24]. In our study less than $20 \mathrm{mil} / \mathrm{ml}$ was considered as oligozoospermia, which may cause significant increase in the amount of gonadotropin hormones and decreased testosterone serum level in compare to normal fertile group. Our study revealed that $\mathrm{FSH}, \mathrm{LH}$, and testosterone evaluation is useful in the management of male infertileity, but the couples with a high risk transferring of a main genetic defect recommended performing molecular screening of AZF partial or subdeletion before any decision for generation.

\section{ACKNOWLEDGEMENTS}

The authors are grateful to Sina Urology Centre of Tehran University of Medical Sciences and Koasar Fertility and Impotency Center for their kind collaboration.

\section{REFERENCES}

[1] Mittal, R.D., Singh, G., Srivastava, A., Pradhan, M., Kesari, A., Makker, A. and Mittal, B.Y. (2004) Chromosome micro-deletions in idiopathic infertility from Northern India. Annales de Génétique, 47, 331-337. doi:10.1016/j.anngen.2004.05.003

[2] Lynch, M., Cram, D.S., Reilly, A., O’Bryan, M.K. and Baker, H.W.G. (2005) The Y chromosome gr/gr subdeletion is associated with male infertility. Molecular Human Reproduction, 11, 507-512. doi:10.1093/molehr/gah191

[3] Madhukar, D. and Rajender, S. (2009) Hormonal treatment of male infertility: Promises and Pitfalls. Journal of Andrology, 30, 95-112. doi:10.2164/jandrol.108.005694

[4] Raicu, F., Popa, L., Apostol, P., Cimponeriu, D., Danl, L., Ilinca, E., et al. (2003) Screening for microdeletions in human Y chromosome AZF candidate genes and male infertility. Journal of Cellular and Molecular Medicine., 7, 43-48. doi:10.1111/j.1582-4934.2003.tb00201.x

[5] Tiepolo, L. and Zuffardi, O. (1976) Localization of factors controlling spermatogenesis in the nonfluorescent portion of the human Y chromosome long arm. Human Genetics, 34, 119-124. doi:10.1007/BF00278879

[6] Reijo, R., Lee, T.Y., Salo, P., Alagappan, R., Brown, L.G., Rosenberg, M., et al. (1995) Diverse spermatogenic defects in humans caused by $\mathrm{Y}$ chromosome deletions encompassing a novel RNA-binding protein gene. Nature Genetics, 10, 383-393. doi:10.1038/ng0895-383

[7] Vogt, P.H., Edelmann, A., Kirsch, S., Henegariu, O., Hirschmann, P., Kiesewetter, F., et al. (1996) Human Y chromosome azoospermia factors (AZF) mapped to different subregions in Yq11. Human Molecular Genetics, 5, 933-943. doi:10.1093/hmg/5.7.933

[8] Kent-First, M., Muallem, A., Shultz , J., Pryor, J., Roberts, 
K., Nolten, W., et al. (1999) Defining regions of the Y-chromosome responsible for male infertility and identification of a fourth AZF region (AZFd) by Y-chromosome microdeletion detection. Molecular Reproduction and Development, 53, 27-41. doi:10.1002/(SICI)1098-2795(199905)53:1<27::AID-M RD4>3.0.CO;2-W

[9] Ferlin, A., Tessari, A., Ganz, F., Marchina, E., Barlati, S., Garolla, A., et al. (2005) Association of partial AZFc region deletions with spermatogenesis impairment and male infertility. Journal of Medical Genetics, 42, 209-213. doi:10.1136/jmg.2004.025833

[10] Repping, S., Skaletsky, H., Brown, L., Van Daalen, S.K., Korver, C.M., Pyntikova, T., et al. (2003) Polymorphism for a 1.6-Mb deletion of the human Y chromosome persists through balance between recurrent mutation and haploid selection. Nature Genetics, 35, 247-251. doi:10.1038/ng1250

[11] Fernandes, S., Huellen, K., Goncalves, J., Dukal, H., Zeisle, J., Souse, M., et al. (2002) High frequency of DAZ1/DAZ2 gene deletions in patient with severe oligozoospermia. Molecular Human Reproduction, 8, 286-298. doi:10.1093/molehr/8.3.286

[12] Repping, S., Saskia, K.M., Van Daalen, S.K., Korver , C. M., Brown, L.G., Marszalek, J.D., et al. (2004) A family of human $\mathrm{Y}$ chromosomes has dispersed throughout northern Eurasia despite a 1.8-Mb deletion in the azoospermia factor c region. Genomics, 83, 1046-1052. doi:10.1016/j.ygeno.2003.12.018

[13] Simoni, M., Bakker, E. and Krausz, C. (2004) EAA/EMQN best practice guidelines for molecular diagnosis of Y-chromosomal microdeletions. State of the ART 2004. International Journal of Andrology, 27, 240-249. doi:10.1111/j.1365-2605.2004.00495.x

[14] Mirfakhraie, R., Mirzajani, F., Mahdi Kalantar, S., Montazeri, M., Salsabili, N., Pourmand, G.R. and Houshmand, M. (2010) High prevalence of AZFb microdeletion in Iranian patients with idiopathic non-obstructive azoospermia. Indian Journal of Medical Research, 132, 265-270.

[15] Babu, S., Sadhnanl, M.D., Swama, M., Padmavathi, P. and Reddy, P.P. (2004) Evaluation of FSH, LH and testosterone levels in different subgroups of infertile males. Indian Journal of Clinical Biochemistry, 19, 45-49. doi:10.1007/BF02872388
[16] Ferlin, A., Arredi, B.A., E Speltra., et al. (2007) Molecular and clinical characterization of $\mathrm{Y}$ chromosome microdeletions in infertile men: A 10-year experience in Italy. The Journal of Clinical Endocrinology \& Metabolism, 97, 762-770.

[17] Nowroozi, M.R. and Radkhah, K. (2008) Serum inhibin B concentration as a prognostic factor for prediction of sperm retrieval in testis biopsy of patients with azoospermia. Archives of Iranian Medicine, 11, 54-56.

[18] Kumar, R., Dada, R. and Gupta, N.P. (2006) Serum FSH levels and testicular histology in infertile men with non obstructive azoospermia and $\mathrm{Y}$ chromosome microdeletions. Indian Journal of Urology, 22, 332-336. doi:10.4103/0970-1591.29119

[19] Claudia, C.M.B., Zuccherato, L.W., Bastos-Rodrigues, L., Santos, F.R. and Pena, S.D.J. (2006) No association found between gr/gr deletions and infertility in Brazilian males. Molecular Human Reproduction, 12, 269-273. doi:10.1093/molehr/gal029

[20] Oates, R.D., Silber, S., Brown, L.G. and Page, D.C. (2002) Clinical characterization of 42 oligospermic or azoospermic men with microdeletion of the AZFc region of the Y chromosome, and of 18 children conceived via ICSI. Human Reproduction, 17, 2813-2824. doi:10.1093/humrep/17.11.2813

[21] Zhang, F., Li, Z., Wen, B., Jiang, J., Shao, M., Zhao, Y., et al. (2006) A frequent partial AZFc deletion does not render an increased risk of spermatogenic impairment in East Asians. Annals of Human Genetics, 70, 304-313. doi:10.1111/j.1529-8817.2005.00231.x

[22] Olive, A., Spira, A. and Multigner, L. (2001) Contribution of environmental factors to the risk of male infertility. Human Reproduction, 16, 1768-1776. doi:10.1093/humrep/16.8.1768

[23] Carrara, R.C.V., Yamasaki, R., Mazucatto, L.F., Veludo, M.A.L., et al. (2004) Somatic and grem cell cytogenetic studies and AZF microdeletion screening in infertile men. Genetics and Molecular Biology, 27, 477-482. doi:10.1590/S1415-47572004000400002

[24] Hellani, A., Al-Huellen, S., Iqbal, M. and Coskun, S. (2006) Y chromosome microdeletion in infertile men with idiopathic olig- or azoospermia. Journal of Experimental \& Clinical Assisted Reproduction, 3, 1. doi:10.1186/1743-1050-3-1 